\title{
Atomization of Ti-64 alloy using the EIGA process: comparison of the characteristics of powders produced in labscale and industrial-scale facilities
}

\author{
Stefan Drawin $^{*}{ }^{1,2}$, Agathe Deborde ${ }^{3}$, Marc Thomas ${ }^{1,2}$, Michel Pierronnet $^{4}$, Layla Sasaki ${ }^{5}$, Jérôme Delfosse ${ }^{6}$, Olivier Godde ${ }^{1,2}$ \\ ${ }^{1}$ Materials and Structures Department, ONERA, Châtillon, ${ }^{2}$ Université Paris-Saclay, Gif-sur-Yvette, ${ }^{3}$ MetaFensch, Uckange, ${ }^{4}$ Erasteel, Paris, ${ }^{5}$ Research \\ and Development Department, Aubert \& Duval, Les Ancizes, ${ }^{6}$ Safran Tech, Magny-les-Hameaux, France
}

\begin{abstract}
$\underline{\text { Abstract }}$
Titanium alloy powders, mostly the Ti-64 alloy with composition Ti-6Al-4V (wt.\%), are extensively used for biomedical and high-demanding applications, e.g. in aeronautics. Advanced powder metallurgy processes like additive manufacturing are strong drivers for the production of high quality powders, insuring a good rheological behavior, a low porosity level in the parts and an adequate roughness. Ideally, fine spherical particles with no volume and surface defects are aimed at.

Inert gas atomization is a process that is able to produce clean powders for such applications, especially for AM. To avoid the chemical reaction of titanium with the commonly used alumina crucibles, a crucible-free configuration has been designed in the EIGA process (Electrode induction melting Inert Gas Atomization). Two EIGA facilities are currently available in France for R\&D purposes: a one-liter (nominal rod diameter/length (mm): 50/500) labscale facility at ONERA and an eight-liter capacity (100/1000) industrial-scale facility at the MetaFensch Institute. Using the smaller facility to screen and optimize atomization parameters and transfer them to the bigger facility is a tempting approach. This communication will show the characteristics of Ti-64 powders produced in both facilities, in terms of particle shape, particle size distribution, presence of satellites and porous particles.
\end{abstract}

\section{Introduction}

Titanium alloys are increasingly used in aeronautics and space (for about $50 \%$ of the world's needs [1]) thanks to their excellent specific mechanical properties and oxidation and corrosion resistance up to moderate temperatures $\left(\sim 500{ }^{\circ} \mathrm{C}\right)$. These alloys are also widely used in biomedical applications (prostheses, implants...). With the advent of additive manufacturing (AM) technologies, the share of titanium in powder form has increased in many industrial sectors. Academic and industrial operators of AM machines have soon detected that some defects found in AM parts, such as voids, inclusions, excessive oxygen and/or nitrogen content, surface roughness, are related to the characteristics of particles (size, shape, roughness, composition, presence of satellites internal or pores...) and of the powder (free and packed density, flowability or spreadability, particle size distribution (PSD)...). Efforts have hence been made to increase the quality of commercial powders available for the various AM processes at an acceptable price increase.

Inert gas atomization provides a good compromise between powder quality and cost [2] for AM and other PM processes. Because of chemical reaction between the melt and alumina, common ceramic crucibles cannot be used to produce the liquid titanium flow. The EIGA (Electrode induction melting Inert Gas Atomization) overcomes this by only melting the lower tip of a vertical titanium rod placed in an induction coil. The free-falling liquid metal is fragmented in a nozzle by a high velocity argon flow, while the rod is continuously moved downwards to feed the small melting zone.

In this study, we investigate the characteristics of Ti-6Al-4V (Ti-64) alloy powders produced by two EIGA facilities using three rod sizes (1, 4 and 8 liters). This is a contribution to the objective of upscaling and industrializing the process by producing larger powder batches for cost reduction and increased quality homogeneity, though maintaining the powder characteristics as constant as possible between the small and the big EIGA facilities. This would also allow R\&D work (alloy development, optimization of atomization parameters) on the small EIGA, requiring lower amounts of materials, though enabling a quick upscaling on the industrial size facility.

\section{Material and experiments}

Material

Two Ti alloy grades have been used: grade 5 (Ti-64) and grade 23 (Ti-64 ELI). The compositions of the bars that were bought for this study are given in Table 1.

Rods were turned out of the bars to yield the diameters adapted to each facility $(50,70$ and $100 \mathrm{~mm})$. For each rod, a conical tip was also turned to ensure the dripping along the facility vertical reference axis.

Table 1. Chemical composition of the atomized rods, and composition standard for grade 23 


\begin{tabular}{|c|c|c|c|c|c|c|c|c|}
\hline Composition (wt.\%) & $\mathbf{T i}$ & Al & $\mathbf{v}$ & $\mathrm{Fe}$ & o & $\mathrm{C}$ & $\mathbf{N}$ & $\mathbf{H}$ \\
\hline \multicolumn{9}{|c|}{ Standard: ASTM F136 Ti-64 ELI (grade 23) } \\
\hline $\min$ & bal. & 5.5 & 3.5 & - & - & - & - & - \\
\hline $\max$ & bal. & 6.5 & 4.5 & 0.25 & 0.13 & 0.08 & 0.05 & 0.0125 \\
\hline \multicolumn{9}{|c|}{ Ø50 ONERA (TA6V Grade 5) } \\
\hline top & bal. & 6.53 & 4.15 & 0.24 & 0.14 & 0.02 & 0.01 & 0.001 \\
\hline bottom & bal. & 6.56 & 4.14 & 0.28 & 0.15 & 0.02 & 0.01 & 0.001 \\
\hline \multicolumn{9}{|c|}{ Ø70 MetaFensch (TA6V Grade 23) } \\
\hline top & bal. & 6.03 & 3.9 & 0.14 & 0.11 & 0.01 & $<0.01$ & - \\
\hline bottom & bal. & 6.07 & 4.0 & 0.16 & 0.10 & 0.01 & $<0.01$ & - \\
\hline \multicolumn{9}{|c|}{ Ø100 MetaFensch (TA6V Grade 23) \#1 } \\
\hline top & bal. & 6.1 & 4.3 & 0.14 & - & 0.02 & 0.02 & 0.001 \\
\hline bottom & bal. & 6.1 & 4.2 & 0.13 & - & 0.02 & 0.02 & 0.001 \\
\hline \multicolumn{9}{|c|}{ Ø100 MetaFensch (TA6V Grade 23) \#2 (for optimized parameters) } \\
\hline top & bal. & 6.12 & 3.93 & 0.191 & 0.104 & 0.0062 & $<0.003$ & 0.001 \\
\hline bottom & bal. & 6.11 & 3.94 & 0.19 & 0.104 & 0.0045 & $<0.003$ & 0.002 \\
\hline
\end{tabular}

\section{The atomization facilities at ONERA and METAFENSCH}

The ONERA atomization tower, thanks to a second melting module (VIGA, with a ceramic crucible) is used mainly to produce Ti-, TiAl-, Nb- and Nibased alloy powders; the MetaFensch tower focuses currently on Ti-alloys, and is operated with rods of diameter $70 \mathrm{~mm}, 100 \mathrm{~mm}$ and $150 \mathrm{~mm}$. The facilities are shown in Figure 1.

The main atomization data are given in Table 2 . 

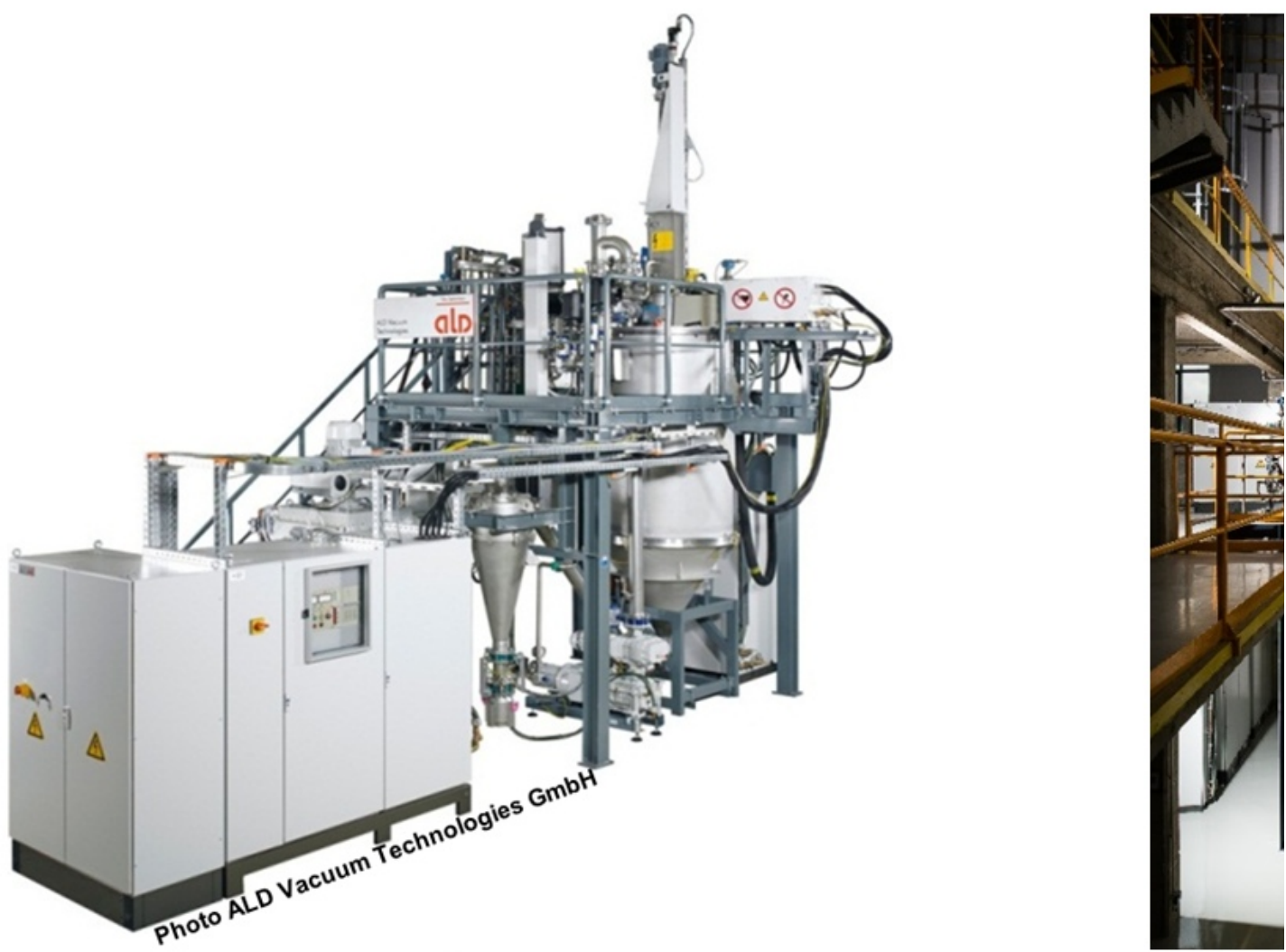

(a)

Figure 1. Pictures of the EIGA facilities, (a) at ONERA (height $\sim 7 \mathrm{~m}$ ) and (b) at MetaFensch (height $\sim 10 \mathrm{~m}$ )

Table 2. Main atomization data of EIGA facilities at ONERA and MetaFensch

\begin{tabular}{|c|c|c|c|c|}
\hline Facility & $\begin{array}{c}\text { Nominal rod } \\
\text { dimension } \\
\text { (diameter / length) }\end{array}$ & $\begin{array}{c}\text { Power supply } \\
\text { capacity (kW) }\end{array}$ & $\begin{array}{c}\text { Atomization gas } \\
\text { pressure range } \\
\text { (bar) }\end{array}$ & $\begin{array}{c}\text { Nominal/Maximal } \\
\text { batch size for Ti-64 (kg) }\end{array}$ \\
\hline ONERA & $50 \mathrm{~mm} / 500 \mathrm{~mm}$ & 60 & $15-45$ & $4-7$ \\
\hline MetaFensch & $\begin{array}{c}70-100-150 \mathrm{~mm} / \\
1000 \mathrm{~mm}\end{array}$ & 240 & $25-50$ & $10-75$ \\
\hline
\end{tabular}

Atomization protocol

Before each atomization run, the installation was evacuated to a primary vacuum and the leak rate was measured to control the airtightness. Then, the tower was filled with argon to $c a$. 1 bar.

Argon was used as the atomization gas and its flowrate was adjusted mostly with gas pressure. Power was switched on to start melting the rod and creating the liquid metal stream that falls into the gas nozzle. Rotation of the rod at low velocity ensures a uniform melting. To have a continuous and stable melt, 
power and feed rate of the rod were adjusted to keep it within the induction coil. The melt rate was calculated using the feed rate, section and density of the rod.

Average values of main atomization parameters (gas and metal flowrates) were measured for each run. In each case, only part of the rod was atomized, yielding a powder quantity from 1 to $7 \mathrm{~kg}$ depending on rod diameter and atomization conditions.

\section{Powder Characterization}

After atomizing, the PSD and morphological data on the powders were measured by using a Retsch Camsizer XT morpho-granulometer (MG). The powder is introduced through a vibrating feeding table, then separated by a pressurized gas jet to ensure proper particles dispersion and agglomerates removal. A set of two high speed cameras (basic and zoom) collect the shape of each particle. After automated image analysis, the MG provides data enabling to plot many particle shape characteristics and volume fraction as a function of their size classes. These size classes are ranging from $0-5 \mu \mathrm{m}$ to above $350 \mu \mathrm{m}$, the minimum resolution of the apparatus being 3-5 $\mu \mathrm{m}$. For reproducibility reasons, measurements were repeated three times per sample.

To describe the PSD, the main parameters studied are $d 10, d 50$ and $d 90$, respectively the diameters under which $10 \%, 50 \%, 90 \%$ volume fraction of particles are classified. $d 50$ is also called the median particle size. For all measurements, the shortest chord of the particle is studied as diameter $\left(x c \_m i n\right.$ in the Camziser).

For morphological data (in volume), the aspect ratio $b / l 3$, corresponding to the ratio between the smallest and the largest length of the particle, was considered. The sphericity $S P H T 3$ was also measured and compared:

$$
\text { Sphericity }=\frac{4 \pi A}{P^{2}}
$$

with $\mathrm{A}$ the measured area covered by a particle projection and $\mathrm{P}$ its measured perimeter.

SEM-FEG (scanning electron microscope Zeiss Merlin, with field-effect electron gun; $5 \mathrm{kV}$ accelerating voltage) analysis has been performed on powders from the $Æ 50$ and $Æ 100$ rods $(0-63 \mu \mathrm{m}$ class) which were poured on a conductive tape; regions where the particles could be individualized were selected for investigation.

In addition, observations and porosity measurements were made through optical analysis on $0-63 \mu \mathrm{m}$ and $63-80 \mu \mathrm{m}$ classes. Atomized powders were mounted and subsequently polished up to a mirror finish. A set of 221 pictures were taken on each sample using an optical microscope at a x100 magnification, to cover a $10 \times 10 \mathrm{~mm}^{2}$ surface. Camera settings such as the exposure time, contrast and brightness were fixed for all observations. For each powder sample, the set of images were then analyzed using the ImageJ software and a grey-level thresholding to identify both particles and their porosity. Measurements were repeated three times per sample to ensure a good reproducibility.

\section{Results}

Three atomization runs were carried out on the EIGA atomizers for different rods diameter: $50 \mathrm{~mm}$ at ONERA, 70 and $100 \mathrm{~mm}$ at MetaFensch. The gas flowrate was set at a value between 31 and $33 \mathrm{~kg} / \mathrm{min}$

Table 3 shows the parameters and PSD analysis of the atomization runs. It can be observed that the median particle size $d 50$ increases with the rod diameter and the consecutive increase in metal flowrate. Consequently, the yield of fine powders (fraction $<45 \mu \mathrm{m}$ ) decreases, especially from $\varnothing 50 \mathrm{and} \varnothing 70 \mathrm{~mm}$ (around $20 \%$ ) to the largest diameter $(11.4 \%$ ). The particles are spherical, but their morphological quality is lower for the MetaFensch runs.

Table 3. Summary of the main atomizing parameters and associated powder characteristics

\begin{tabular}{|c|c|c|c|}
\hline & Ø50 ONERA & Ø70 MetaFensch & Ø100 MetaFensch \\
\hline Rod diameter (mm) & $\mathbf{5 0}$ & $\mathbf{7 0}$ & $\mathbf{1 0 0}$ \\
\hline Composition & Grade 5 & Grade 23 & Grade 23 \\
\hline
\end{tabular}




\begin{tabular}{|c|c|c|c|}
\hline Gas flowrate $Q g(\mathrm{~kg} / \mathrm{min})$ & 33 & 31 & 31 \\
\hline Metal flowrate $Q m(\mathrm{~kg} / \mathrm{min})$ & 0.3 & 0.7 & 1.4 \\
\hline$Q g / Q m$ (GMR) & 106 & 44 & 22 \\
\hline$d 10(\mu \mathrm{m})$ & 32 & 34 & 43 \\
\hline$d 50(\mu \mathrm{m})$ & 75 & 79 & 99 \\
\hline$d 90(\mu \mathrm{m})$ & 170 & 185 & 192 \\
\hline Volume $\%<14 \mu \mathrm{m}$ & 1.1 & 0.9 & 0.5 \\
\hline Volume $\%<45 \mu \mathrm{m}$ & 21.5 & 18.7 & 11.4 \\
\hline Volume $\%<105 \mu \mathrm{m}$ & 68.1 & 66.1 & 53.8 \\
\hline Sphericity (SPHT3) & 0.93 & 0.87 & 0.88 \\
\hline Aspect ratio $(b / l 3)$ & 0.88 & 0.82 & 0.83 \\
\hline
\end{tabular}

Many particle size distributions in liquid metal atomization processes conform to a log-normal (L-N) distribution $f(D)$ [3]:

$$
f(D)=\frac{1}{\sqrt{2 \pi} D \sigma} \exp \left(-\frac{1}{2 \sigma^{2}}(\ln (D)-\ln (d 50))^{2}\right)
$$

where $\mathrm{D}$ is the particle diameter and $\sigma$ the standard deviation of the distribution. This conformity can be checked by drawing (Figure 2) the experimental cumulative volume data $F(D)$ in a L-N representation, $\operatorname{erf}[x]$ being the error function:

$$
F(D)=\int_{0}^{D} f(x) d x=\frac{1}{2}\left(1+\operatorname{erf}\left[\frac{\ln (D)-\ln (d 50)}{\sqrt{2} \sigma}\right]\right)
$$

In Figure 2, the red L-N line is the best fit to the experimental data (determination of $d 50$ and $\sigma$ by the least squares method). The standard deviation is given by the inferred L-N law, but can be estimated by calculating the ratios $d 84 / d 50$ and $d 50 / d 16$ [4]. 

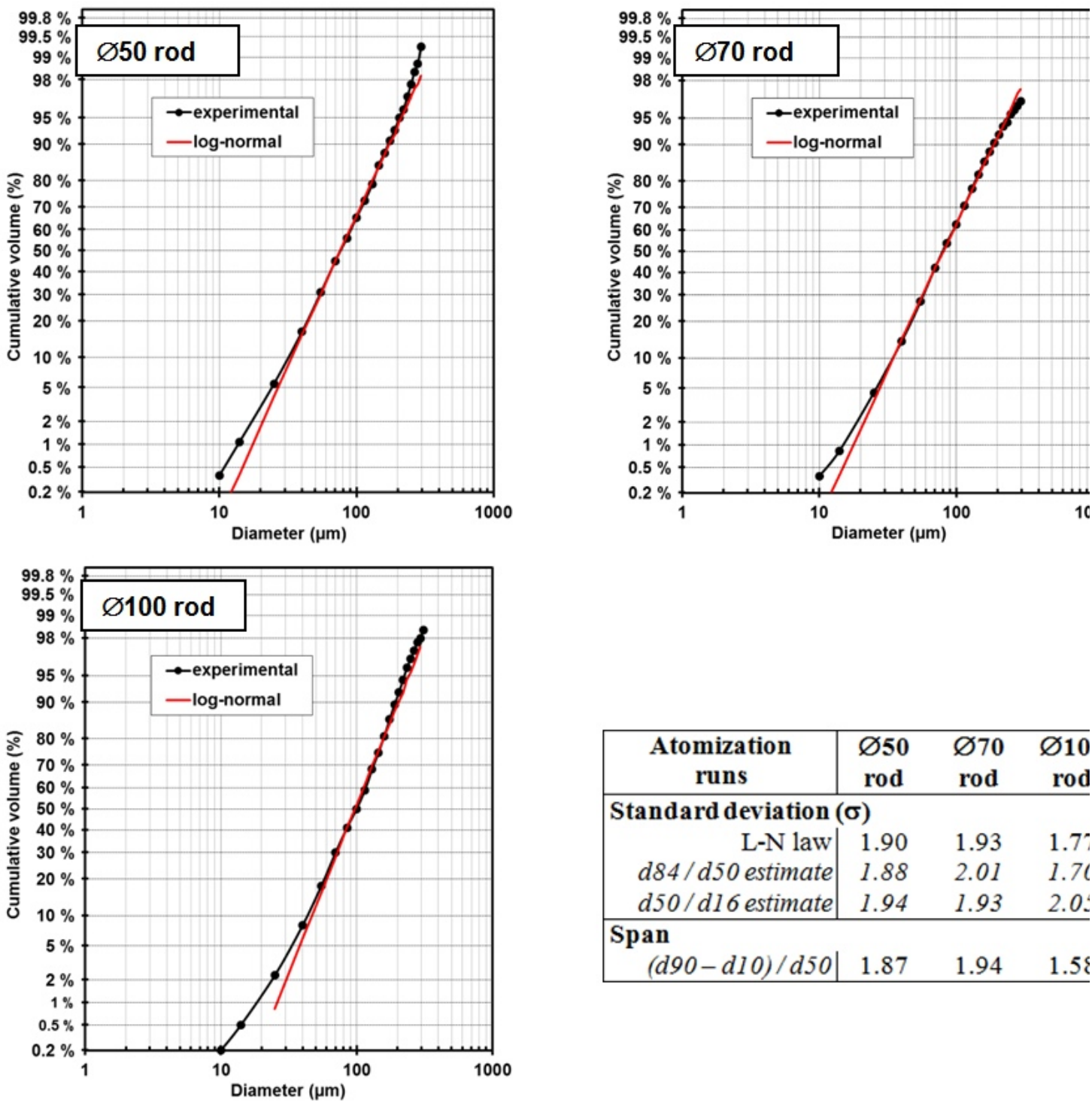

\begin{tabular}{|c|ccc}
\hline $\begin{array}{c}\text { Atomization } \\
\text { runs }\end{array}$ & $\begin{array}{c}\varnothing 50 \\
\text { rod }\end{array}$ & $\begin{array}{c}\varnothing 70 \\
\text { rod }\end{array}$ & $\begin{array}{r}\varnothing 10 \\
\text { rod }\end{array}$ \\
\hline \multicolumn{2}{|c|}{ Ltandard deviation $(\sigma)$} \\
L-N law & 1.90 & 1.93 & 1.7 \\
d84/d50 estimate & 1.88 & 2.01 & 1.7 \\
$d 50 / d 16$ estimate & 1.94 & 1.93 & 2.0 \\
\hline Span & & & \\
$(d 90-d 10) / d 50$ & 1.87 & 1.94 & 1.5 \\
\hline
\end{tabular}

Figure 2. Comparison of experimental cumulative volume curve and cumulative L-N curves for the three atomization runs

Particle Size Distribution and morphological data

The PSD of the three as-atomized powders are shown in Figure 3. The distributions of runs $\varnothing 50 \mathrm{~mm}$ and $\varnothing 70 \mathrm{~mm}$ are similar. However, for the $100 \mathrm{~mm}$ diameter, the PSD is shifted towards the production of coarser powders. An increase of $24 \mu \mathrm{m}$ in the $d 50$ is observed between diameters 50 and 100 mm, along with the increase of the melt rate from 0.3 to $1.4 \mathrm{~kg} / \mathrm{min}$. 
It is also observed that the powder shape quality decreases with increasing rod diameter and consecutive increased metal flow. In Figure 4, the sphericity calculated by the MG is given as a function of particle size. Two different behaviors can be noticed: on the one hand, a stable sphericity around $93 \%$ for the $50 \mathrm{~mm}$ run, and on the other hand, a significant and linear decrease in sphericity with increasing particle size, above $150 \mu \mathrm{m}$, for the $50 \mathrm{~mm}$ and $70 \mathrm{~mm}$ runs, with a sphericity ranging from $92 \%$ to $80 \%$. Yet, within the fraction of interest for $\mathrm{AM}(<105 \mu \mathrm{m})$, both sphericity factors are stable.

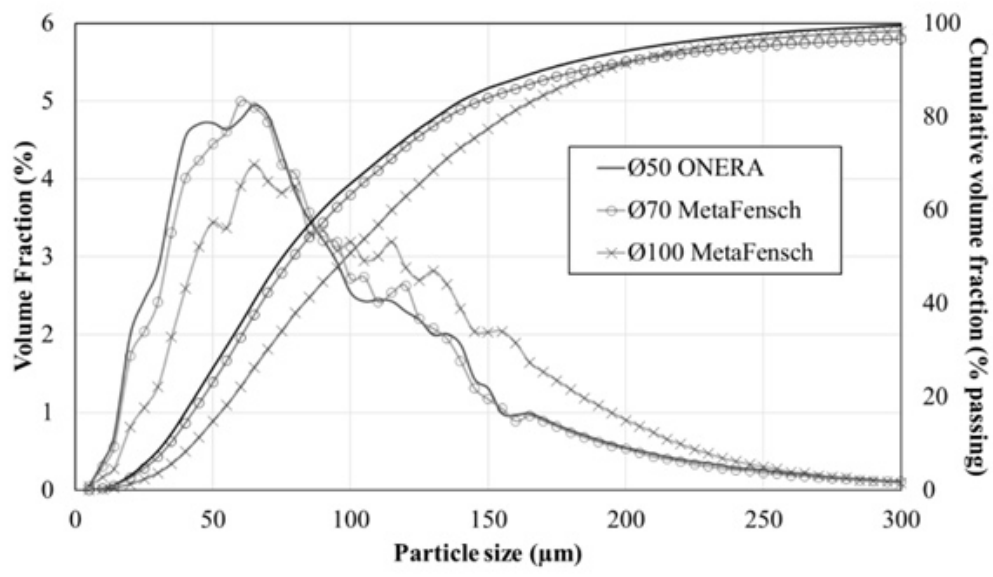

Figure 3. PSD of the three runs

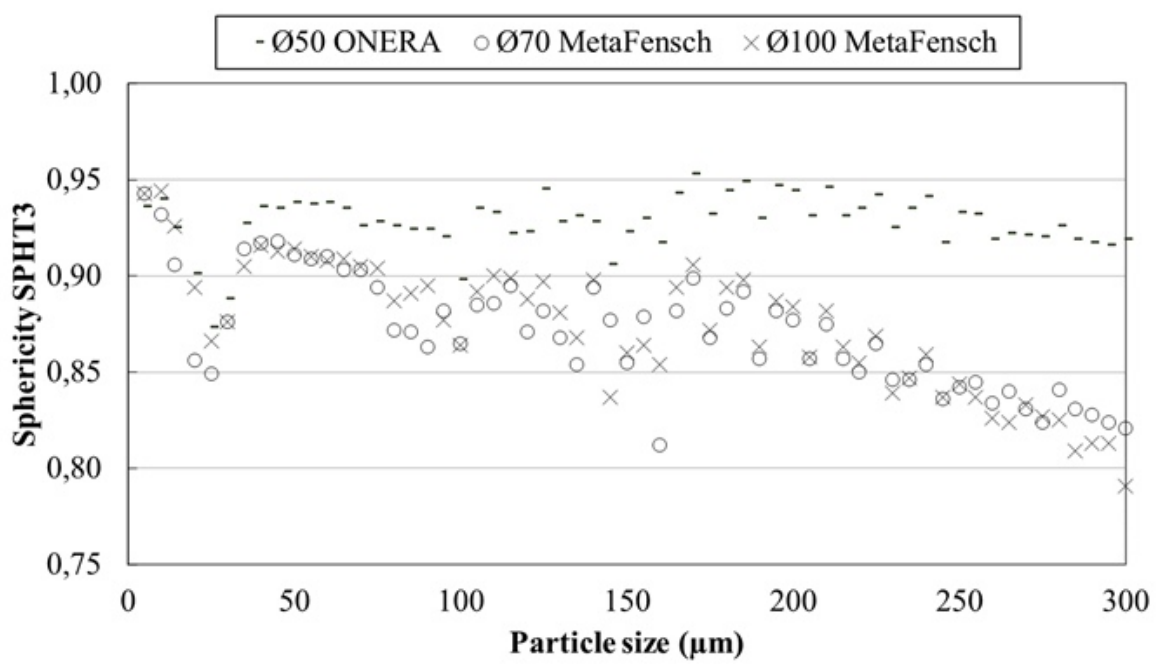

Figure 4. Sphericity factor as a function of particle diameter

The origin of this behavior difference depending on the diameter and/or facilities is not known at this point, but some elements will be proposed in the discussion section. 
SEM analysis

Micrographs of $0-63 \mu \mathrm{m}$ powders obtained by atomizing the $\varnothing 50 \mathrm{~mm}$ and $\varnothing 100 \mathrm{~mm}$ rods are shown in Figure 5 (backscattered electron imaging mode), at the same magnification. Their morphologies look very similar, with mostly spherical particles, some defects like open pores and elongated particles, but the Ø100 rod powder seems to exhibit a higher density of satellites and agglomerates: this is consistent with the fact that the measured shape quality (through the sphericity factor, Figure 4) is significantly lower for the Ø100 rod powder compared to the Ø50 rod powder.

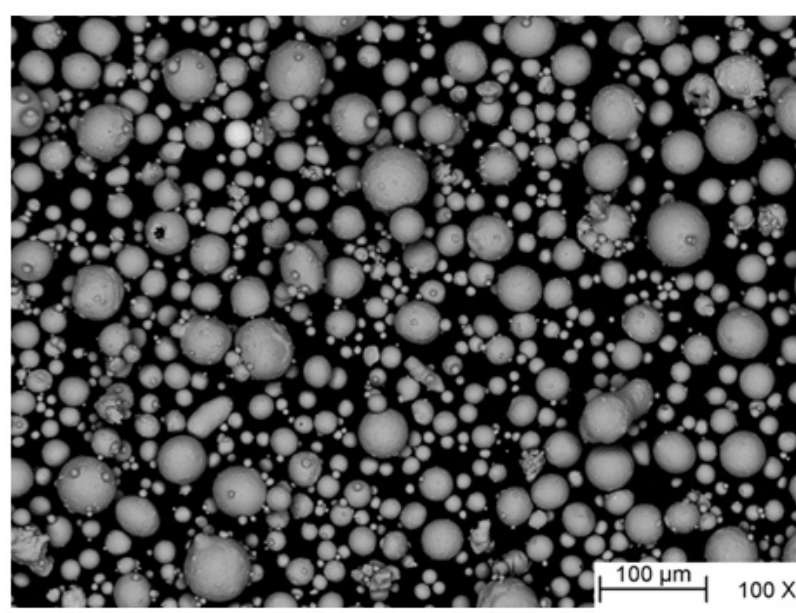

(a)

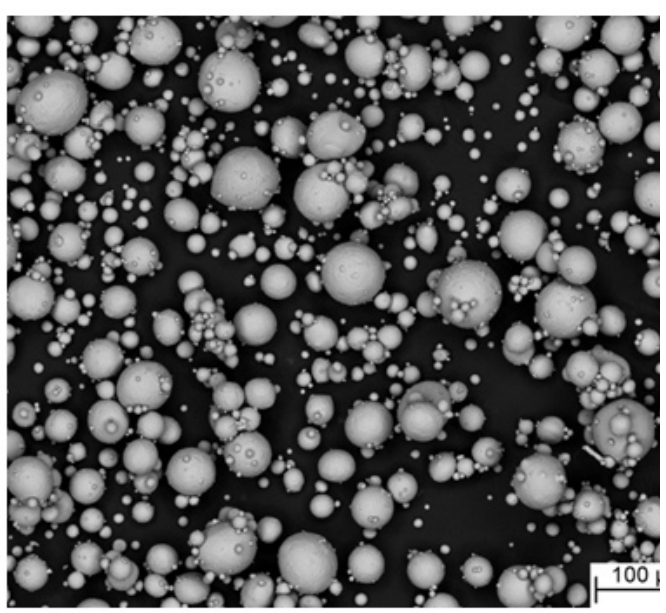

(b)

Figure 5. SEM images of the powders (sieved to $<63 \mu \mathrm{m}$ ) obtained from the (a) Ø50 rod and the (b) Ø100 rod

Porosity

The pictures of porosity analysis are shown in Figure 6 and the porosity data of the different samples are given in Table 4. The optical observations show relatively few pores for both $<63$ and 63-80 $\mu \mathrm{m}$ fractions in both rod diameters. The quantitative analysis shows however a slight increase in porosity with increasing particle size. At this stage, no effect of the rod diameter on the porosity levels can be highlighted. The slight porosity increase is related mainly to the powder size. The standard deviation on the measurements is relatively high, as a significantly low level of porosity is achieved on the powders of the study. 


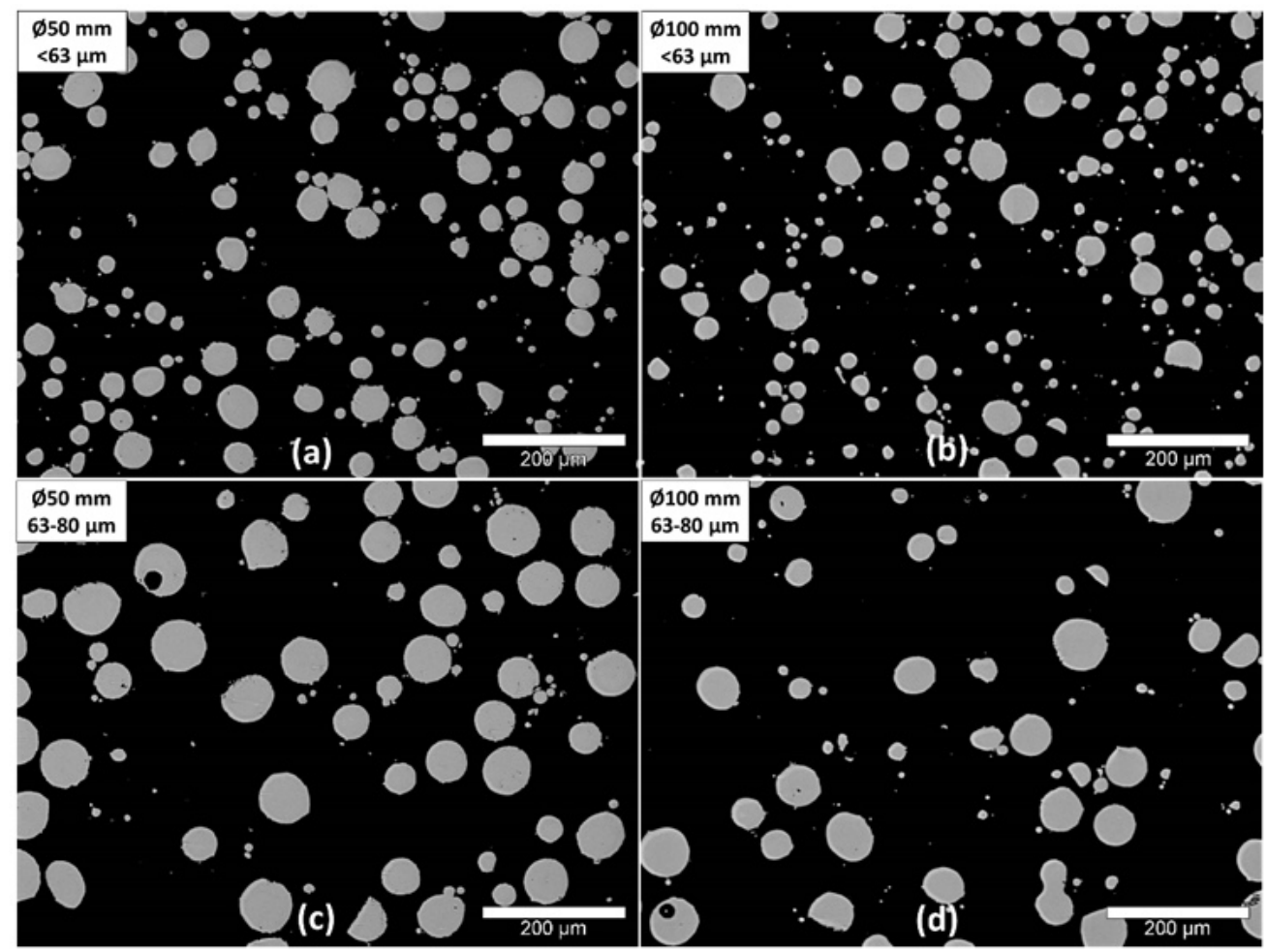

Figure 6. Porosity analysis for $\varnothing 50$ rod (a and c) and $\varnothing 100$ (b and d), for different particle size classes

Table 4. Porosity data

\begin{tabular}{|c|cc|cc|}
\hline Rod diameter (mm) & \multicolumn{2}{|c|}{ Ø50 } & \multicolumn{2}{|c|}{ Ø100 } \\
\hline Particle size range $(\mu \mathrm{m})$ & $<63$ & $63-80$ & $<63$ & $63-80$ \\
Average porosity (surface \%) & 0.1 & 0.2 & 0.1 & 0.2 \\
Standard deviation (surface \%) & 0.1 & 0.1 & 0.1 & 0.1 \\
\hline
\end{tabular}

\section{Discussion}

As seen in Figure 2, for all three atomizations, both experimental and L-N curves are very close in most of the particle diameter range (ca. $d 10$ to $d 90$ ), indicating that the atomizations have been run in steady state conditions. The deviation between the two curves at small particle sizes has been quite systematically observed at ONERA on distributions obtained by sieving or laser diffraction, suggesting that more fines have been produced then expected by the L-N law; it is not known if this originates from the atomization conditions used so far or from a lack of validity of the log-normal law for small 
particle sizes. Figure 2 shows also that the estimations of the standard deviation from experimental data differ slightly from $\sigma$, which reflects the deviation of the experimental and log-normal curves at small particle sizes.

The metal flowrate is the main atomization parameter changing with rod diameter. An increase in the particle size is observed when increasing the melt rate at constant gas parameters. The largest difference on PSD is seen from the rods of diameter 70 and $100 \mathrm{~mm}$. This result could highlight the existence of a threshold in the melt rate between 0.7 and $1.4 \mathrm{~kg} /$ min leading to the increase of the $d 50$.

A difference in shape characteristics is noticed between the two facilities, with a higher sphericity at ONERA. This observation could be correlated with the presence of more satellites on the powder produced at MetaFensch. Satellites are created during the atomization, when smaller particles stick to bigger ones during their solidification. Increased melt rates lead to increased particles number densities, which could be a reason for more collisions and decreased morphological quality. It could also be a consequence of the increased equipment size and different gas recirculation configurations inside the two facilities, inducing more or less satellites. No difference in particle porosity was observed, neither for the various the rod diameters, nor between the two facilities.

However, even at increased metal flow rates, an optimization of the powder produced with large rod diameter is possible. The Figure 7 shows the PSD of an atomization run carried out at MetaFensch with optimized parameters.

With a $d 50$ of $85 \mu \mathrm{m}$, the results for the optimized $\varnothing 100 \mathrm{~mm}$ run approaches the PSD for atomization of smaller diameter. Shape characteristics are in the range of the powders atomized at MetaFensch.

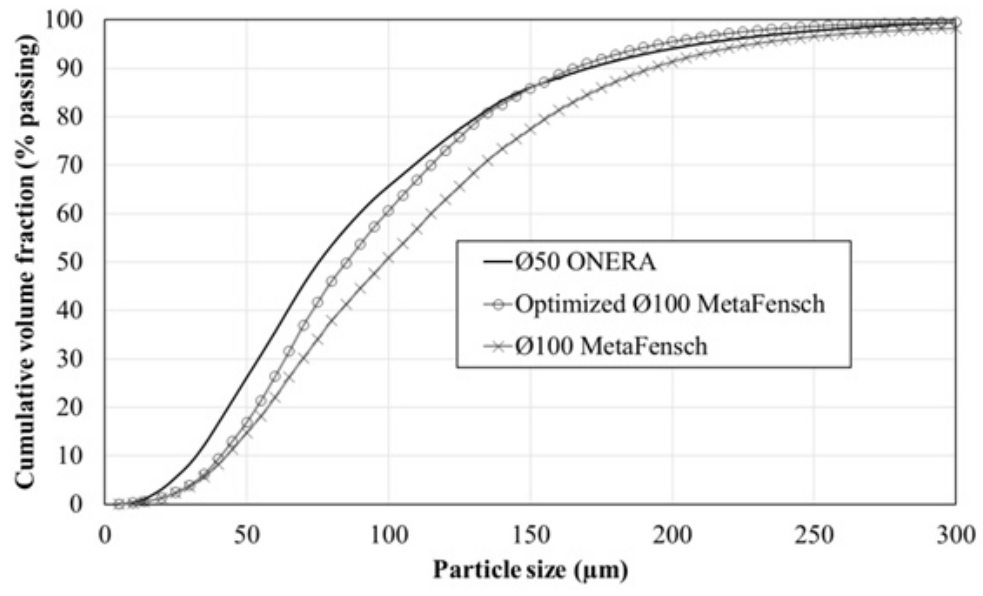

Figure 7. Particle Size Distribution of the optimized atomization run with $\emptyset 100$ compared to the studied runs

The optimization can be explained using the empirical equation described by Lubanska to evaluate the influence of several parameters on the particle size [5]:

$$
d_{50}=K \cdot D \cdot\left(\frac{v_{m}}{v_{g} W e}\left(1+\frac{Q_{m}}{Q_{g}}\right)\right)^{1 / 2}
$$

with $K$ a constant, $D$ the diameter of the metal stream, $Q m$ the metal flowrate, $Q g$ the gas flowrate, $v_{\mathrm{m}, \mathrm{g}}$ the cinematic viscosities (respectively for liquid metal $m$ and gas $g$ ) and $W e$ the Weber number.

Considering the accessible parameters when atomizing Ti-64 on an EIGA facility, metal and gas flowrates and stream diameter are the main parameters to influence PSD. As the melt rate increases with the rod diameter, increasing the gas flowrate is a good way to decrease the $d 50$ and produce finer powder. 


\section{Conclusion}

Atomization runs of Ti-64 rods from 50 to $100 \mathrm{~mm}$ in diameter have been carried out on two different EIGA facilities. This process allows producing mostly non-porous and spherical particles, in the particle diameter range investigated, and with a good correlation with the log-normal law.

Concerning the upscaling of the process with larger rods, the main trends are conserved but keeping the PSD stable between the Ø50 and Ø100 rods is not straightforward. Some levers are left to achieve a stabilized PSD, in particular through atomization pressure. A change in particle morphology is also observed with increasing diameter, with a loss of sphericity, and an increased amount of satellites.

The powder characteristics optimization while upscaling the process requires a better understanding of the atomization phenomena. A better control on other levers such as melting parameters and gas spray could be investigated by means of modelling.

A focus was made on particle size, sphericity and porosity analyses. Study of the rheological behavior of the powders, which is important for AM processes, is to be done to complete the comparison depending on the size of the EIGA facility and atomization parameters.

\section{Acknowledgements}

This work has been supported by the French State under the "Investissements d'Avenir" program managed by ANR through the MATMECA project (reference ANR-10-EQPX-37). MetaFensch acknowledges the support of the French "Investissements d'Avenir" program, the French environmental agency (ADEME) and the European FEDER program.

The authors are also grateful to Raphaël Hammes (MetaFensch) and Nicolas Perrin (Aubert\&Duval) for atomization runs, Aurélien Chabrier and Charlotte Mayer (Aubert\&Duval) for porosity measurements, and Nicolas Horezan (ONERA) for SEM analyses.

\section{References}

[1] Report on titanium for 2015-2017, public edition (2017), www.mineralinfo.fr/sites/default/files/upload/ documents/louvigne_titane_rapport_20152017_edition_publique.pdf, retrieved 10/04/2019

[2] P. Sun, Z.Z. Fang, Y. Zhang and Y. Xia, JOM 69 (2017) 1853-1850

[3] A.J Yule and J.J. Dunkley, Atomization of Melts, 1994, Oxford University Press (London)

[4] . Liu, Science and engineering of droplets: fundamentals and applications, 1999, Noyes Publications (Park Ridge, USA)

[5] H. Lubanska, JOM 22 (1970) 45-49 